\title{
Aplicação aérea de fungicidas com diferentes equipamentos e volumes sobre a produtividade, qualidade de grãos e controle de doenças em arroz irrigado
}

\author{
Aerial application of fungicide with different equipment and application volume on grain quality, \\ productivity and disease control of irrigated rice
}

Tânia Bayer ${ }^{\mathrm{I}}$ Alci Enimar Loeck ${ }^{\mathrm{II}}$ Milton Fernando Cabezas Guerrero ${ }^{\mathrm{III}}$ Moacir Cardoso Elias ${ }^{\mathrm{IV}}$

RESUMO

Os tratamentos fitossanitários na cultura do arroz irrigado geralmente são realizados via aplicação aérea. Por isso, o trabalho objetivou avaliar a produtividade, qualidade do grão e incidência de doenças em arroz da cultivar 'Puitá Inta CL'através da aplicação dos fungicidas Azoxistrobina e Difenoconazol com bicos defletores, 20 e 30L ha-1, bicos cônicos 20 e 30L ha e atomizadores rotativos de disco 10 e $15 \mathrm{~L} \mathrm{ha}^{-1}$. Os tratamentos

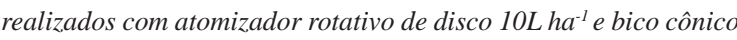

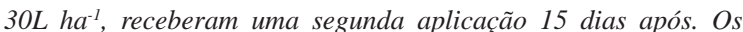
parâmetros avaliados foram os níveis de doenças foliares, peso de mil grãos, número de grãos por panícula, patologia de sementes, renda e rendimento. Não se verificou nenhuma diferença entre os tratamentos em nível de campo, entretanto, as avaliações póscolheita revelaram importante controle dos fungos Fusarium sp. Gerlachia sp. e Bipolaris sp.

Palavras-chave: Oryza sativa, aeroaplicação, patógenos, patologia de sementes.

\section{ABSTRACT}

Phytossanitary treatment on irrigated rice are usually done by aerial application. In face of that, the aim of this project was to evaluate yield, grain quality and disease in rice $C V$ Puitá Inta CL through the fungicide Azoxystrobin+difenoconazole application with 20 and $30 \mathrm{~L} \mathrm{ha}^{-1}$ using deflecting nozzles, 20 and

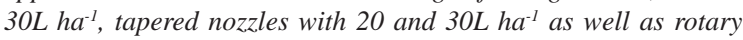

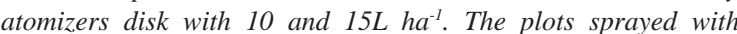
rotary atomizer disk using $10 \mathrm{~L} \mathrm{ha}^{-1}$ and tapered nozzles using $30 \mathrm{~L}$ $h a^{-1}$, received a second application15 days later. The evaluated parameter were leaves disease control, yield, income and grain pathology. There were no differences detected between treatments in the field, however, the assessments revealed important post harvest control of Fusarium sp., Gerlachia sp. and Bipolaris sp.
Key words: Oryza sativa, aero-Application, pathogens, seed pathology.

\section{INTRODUÇÃO}

A qualidade de grãos e sementes de arroz irrigado é um fator de grande importância no momento da comercialização da semente (MARZARI et al., 2007). A cultura do arroz é afetada por diversos fatores bióticos, sendo as doenças fúngicas responsáveis por danos que variam entre 20 e $50 \%$ na produtividade das lavouras de arroz no Rio Grande do Sul (BALARDIN \& BORIN, 2001). Segundo ARAÚJO \& GONTOW (1993), no início da década de 1990, apenas $1 \%$ das aplicações de produtos fitossanitários em arroz irrigado era direcionado ao controle de doenças. $\mathrm{O}$ uso de fungicidas, no Estado do Rio Grande do Sul, passou de 50.000ha em 2003 para 830.000 ha em 2008. Esta expansão se deve principalmente à ocorrência de epidemias da cárie do grão, a partir da safra 2003-2004, quando, em algumas lavouras, as perdas chegaram a $60 \%$ (ZEMOLIN, 2009).

Os danos mais significativos, no Sul do Brasil, estão relacionados com a incidência da mancha-parda (Bipolaris oryzae) e escaldadura (Gerlachia oryzae). Também tem sido observada, de forma secundária ou localizada, a incidência de mancha-das-bainhas (Rhizoctonia oryzae), manchaestreita (Cercospora oryzae) e mancha-de-alternária

\footnotetext{
IDepartamento de Fitossanidade, Faculdade de Agronomia Eliseu Maciel (FAEM) Universidade Federal de Pelotas (UFPel), 96010-900, Pelotas, RS, Brasil. E-mail: tania_bayer@hotmail.com. Autor para correspondência.

IDepartamento de Fitossanidade, UFPel, Pelotas, RS, Brasil.

III Universidad Técnica Eestatal de Quevedo, Campus "Ingeniero Manuel Haz Álvarez", Quevedo, Los Ríos, Ecuador.

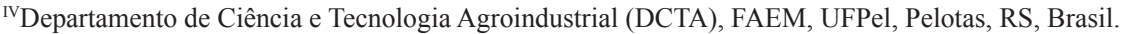
Recebido 27.06.13 Aprovado 02.12.13 Devolvido pelo autor 11.06.14 CR-2013-0886.R1
} 
(Alternaria alternata), segundo CELMER et al. (2007).

Diversos estudos foram realizados com o objetivo de verificar resposta ao controle químico de doenças na cultura do arroz (CELMER et al., 2007). A aplicação de fungicidas tem se revelado uma medida eficaz de controle, como observado por OTTONI et al. (2000), que conseguiram bom controle da mancha-parda na cultivar 'Maravilha' com aplicação de fungicidas.

CORRÊA (2006) verificou que a presença de fungos nas sementes é um problema importante, não só durante o período de armazenamento como também durante a germinação e emergência no campo, podendo torná-las desuniformes ou inaptas para produzir um bom estande.

Segundo MAPA (2009), o objetivo do teste de sanidade é determinar o estado sanitário de uma amostra de sementes, para fornecer informações na comparação da qualidade entre lotes, além de detectar patógenos transmissíveis, via semente, que servem de inóculo inicial, comprometendo a germinação e vigor das sementes no campo.

O rendimento de grãos inteiros, quebrados e com defeitos são os principais parâmetros considerados na avaliação comercial do arroz para a determinação da qualidade e do preço, segundo AMATO \& ELIAS (2005). Grãos infectados com Bipolaris sp. apresentam-se manchados e gessados, o que diminui a qualidade do produto para a indústria(PRABHU \& FILIPPI, 1997), o que justifica seu controle.

Dessa forma, o objetivo deste trabalho foi avaliar a produtividade, a qualidade dos grãos de arroz, os níveis de doenças, renda e rendimento, patologia das sementes, peso de mil grãos e número de grãos por panícula, da cultivar de arroz 'Puitá Inta CL' através da aplicação aérea dos fungicidas (Azoxistrobina 250g + Difenoconazol 250g), com diferentes equipamentos, taxas de aplicação.

\section{MATERIAL E MÉTODOS}

O experimento foi realizado no município de Camaquã, Rio Grande do Sul, latitude 30 56' 59" $\mathrm{S}$, longitude $51^{\circ} 45^{\prime} 22,29^{\prime}$ ' $\mathrm{O}$, e altitude de $17 \mathrm{~m}$, no ano agrícola 2009/2010 com a cultivar de arroz 'Puitá Inta CL'. A área experimental totalizou 75,6 hectares, que foram divididos em nove talhões com 210 metros de largura e 400metros de comprimento.

A semeadura foi realizada com espaçamento de $0,20 \mathrm{~m}$ entre fileiras, com densidade de 65 sementes por metro linear. A pulverização foi realizada com avião agrícola Cessnaag truck, modelo A188B equipado com fluxômetro Interflow e equipamentos previamente montados em barras. A aplicação do fungicida foi realizada durante a excerção da panícula, estádio R3 (COUNCE et al., 2000), que ocorreu aos 85 dias após a semeadura. As caldas de pulverização foram preparadas em tanque com capacidade de 200 litros, obedecendo a seguinte ordem: 80 litros de água, sendo a preparação feita na seguinte forma: 80 litros de água, acrescentando-se, pela ordem, os fungicidas, os adjuvantes Agróleo ${ }^{\circledR}$ e Nimbus ${ }^{\circledR}$, ambos a $0,5 \mathrm{~L} \mathrm{ha}^{-1}$ e completou-se o tanque até os 200 litros com o sistema de agitação acionado, para depois ser enviado ao hopper do avião e imediatamente aplicado.

A altura de vôo foi de 3 metros para bicos defletores e cônicos e de 4 metros para atomizadores rotativos de discos. Os bicos defletores ou de impacto utilizados foram da marca Stol, de jato leque calibrados para vazões de $20 \mathrm{~L} \mathrm{ha}^{-1}$ e $30 \mathrm{~L} \mathrm{ha}^{-1}$. Os bicos cônicos utilizados para aplicar $20 \mathrm{~L} \mathrm{ha}^{-1} \mathrm{e} 30 \mathrm{~L}$ $\mathrm{ha}^{-1}$ foram da marca Travicar, equipados com ponta e core. As atomizações com $10 \mathrm{~L} \mathrm{ha}^{-1} \mathrm{e} 15 \mathrm{~L} \mathrm{ha}^{-1}$ foram realizadas com atomizadores rotativos de discos da marca Turboaero.

O delineamento foi inteiramente casualizado com cinco repetições. Os fungicidas utilizados foram Azoxistrobina $250 \mathrm{~g}+$ Difenoconazol $250 \mathrm{~g}$, nas doses de $0,4 \mathrm{~L}$ ha $^{-1}+0,15 \mathrm{~L}$ $\mathrm{ha}^{-1}$, respectivamente. As parcelas pulverizadas com atomizador rotativo de disco $10 \mathrm{~L} \mathrm{ha}^{-1}$ e bico cônico $30 \mathrm{~L} \mathrm{ha}^{-1}$ receberam uma segunda aplicação 15 dias após a primeira. Em todos os tratamentos, utilizouse o adjuvante Nimbus ${ }^{\circledR} 0,5 \mathrm{~L} \mathrm{ha}^{-1} \mathrm{e}$, nos tratamentos com Atomizadores Rotativos, acrescentou-se mais 0,5 L ha ${ }^{-1}$ de Agróleo $^{\circledR}$.

A produtividade foi avaliada colhendo-se aleatoriamente uma área de $2 \mathrm{~m}^{2}$ em cada parcela. Após a trilha baixou-se a umidade dos grãos para $13 \%$. No campo foram realizadas cinco avaliações da ocorrência de doenças que iniciaram no dia da aplicação, aos 58 dias após a semeadura, seguidas aos 15, 30, 50 e 56 dias após a aplicação em áreas previamente demarcadas dentro dos talhões.

Os fungos que ocorreram naturalmente foram Bipolaris sp., causador da mancha parda e Gerlachia sp., responsável pela escaldadura nas folhas. A avaliação da severidade das doenças foi realizada de forma aleatória em 10 folhas bandeiras e 10 folhas bandeiras-1, totalizando 20 folhas por repetição, e 100 folhas por tratamento, avaliando-se a porcentagem de área foliar atacada e a incidência das doenças. 
O número médio de grãos por panícula foi obtido de 25 panículas de cada parcela. O peso de mil grãos foi obtido a partir da contagem de 500 grãos por repetição e extrapolado para mil. Os grãos foram colhidos com umidade ao redor de $20 \%$, secos em secador estacionário piloto, à temperatura de $30^{\circ} \mathrm{C}$, até $13 \%$. Após foram acondicionados em sacos de ráfia durante 30 dias para estabilização das amostras e beneficiadas pelo processo branco polido, em engenho de provas modelo Zaccaria, de acordo com o manual do equipamento.

As amostras foram analisadas no Laboratório de Pós-Colheita, Industrialização e Qualidade de Grãos, do Departamento de Ciência e Tecnologia Agroindustrial, da Faculdade de Agronomia Eliseu Maciel, da Universidade Federal de Pelotas, de acordo com BRASIL (2010). Cem gramas de amostra descascada em equipamento de engenho de provas, marca Suzuki, separaram os grãos com cascas remanescentes (marinheiros) dos esbramados (grãos integrais). Com os grãos esbramados, realizou-se polimento, peso da mesma amostra e separação de grãos inteiros e quebrados. A confirmação de grãos inteiros foi realizada com auxílio de paquímetro digital, marca ZAAS. Foram considerados grãos inteiros aqueles que apresentaram pelo menos $3 / 4$ do seu comprimento. Dessa forma, em se tratando de uma variedade que possui o grão com $6,0 \mathrm{~mm}$ de comprimento, foi considerado inteiro aquele que apresentou comprimento $\geq 4,5 \mathrm{~mm}$.

Após a separação de grãos inteiros e quebrados, estes foram separados por defeitos nas categorias de grão gessado e manchado. Foram considerados grãos gessados os descascados ou polidos, inteiros ou quebrados que apresentaram metade ou mais de sua estrutura ou superfície com coloração opaca de aspecto farinhoso ou semelhante ao gesso. Como manchado, foi considerado o grão descascado e polido, inteiro ou quebrado que apresentou mancha escura ou esbranquiçada.

A patologia de sementes foi avaliada conforme BRASIL (1992), colocando-se 400 sementes por repetição sobre papel filtro umedecido em caixa Germ-Box. A incubação foi de 7 dias a $20 \pm 2^{\circ} \mathrm{C}$, com regime intermitente de 12 horas luz/12 horas escuro.

Os dados foram submetidos à análise de variância e as médias foram comparadas pelo teste de Tukey ao nível fiducial de 5\%. O software estatístico utilizado foi SAS, com procedimento ANOVA. Os dados de doenças foram transformados para arc seno $\sqrt{\frac{x}{100}}$ e os de renda e rendimento para, $\sqrt{x}+0,5$, devido a não normalidade da distribuição dos dados.

\section{RESULTADOS E DISCUSSÃO}

As doenças que ocorreram foram a mancha parda (Bipolaris sp.) e a escaldadura (Gerlachia sp.) (Figura 1).

Na primeira, segunda e terceira avaliação $(0$, 15, 30 dias após a aplicação), não foram encontrados sintomas de doenças, provavelmente devido às condições meteorológicas pouco favoráveis para o estabelecimento da doença e baixa pressão de inóculo. Somente na quarta e quinta avaliação, aos 50 e 56 dias após a aplicação do fungicida, a incidência foi maior. Durante todo o período, a severidade de doenças foi baixa, com exceção para o patógeno Gerlachia sp. (Figura 1).

Todos os tratamentos controlaram Bipolaris sp. e Gerlachia sp. Nesse sentido, CELMER et al. (2007) demonstraram que o controle de doenças é uma importante ferramenta para manutenção da estabilidade de produção de grãos da cultura do arroz. Segundo MARZARI et al. (2007), a diminuição da severidade de doenças, pelo controle químico, propicia o aumento da produtividade, fatos semelhantes aos encontrados por SLATON et al. (2003) e FAGERIA \& PRABHU (2004).

Todos os equipamentos, exceto Atomizador Rotativo de Disco com volume de $10 \mathrm{~L} \mathrm{ha}^{-1}(2 \mathrm{x})$ proporcionaram um incremento de produtividade ao redor de 19\% (Tabela 1), diferente de BAYER et al. (2011), que não encontraram diferenças de produtividade quando os produtos foram aplicados com bicos hidráulicos, atomizadores rotativos de discos e eletrostáticos na cultivar 'Qualimax 1'. Isso pode estar relacionado com a estrutura da planta, que apresenta um dossel mais fechado em relação a cultivar 'Puitá Inta CL', assim como relataram CELMER \& BALARDIN (2003) de que a resposta à aplicação de fungicidas é diferente para cada cultivar.

$\mathrm{O}$ arroz pulverizado com bico defletor apresentou maior número de grãos por panícula, diferentemente do que ocorreu com o bico cônico. Entretanto, observou-se compensação em relação à produtividade, em que maior número de grãos por panícula resultou em menor peso do grão.

$\mathrm{O}$ aumento de produtividade também foi observado por MACIEL \& TRONCHONI (2003) quando conseguiram um acréscimo no rendimento de grãos da ordem de $20 \%$, o que atribuíram ao controle químico das doenças foliares na cultivar 'IRGA 417' com Azoxistrobina. Da mesma forma, DALLAGNOL et al. (2006) conseguiram cerca de $42,10 \%$ de aumento de produtividade com aplicação 


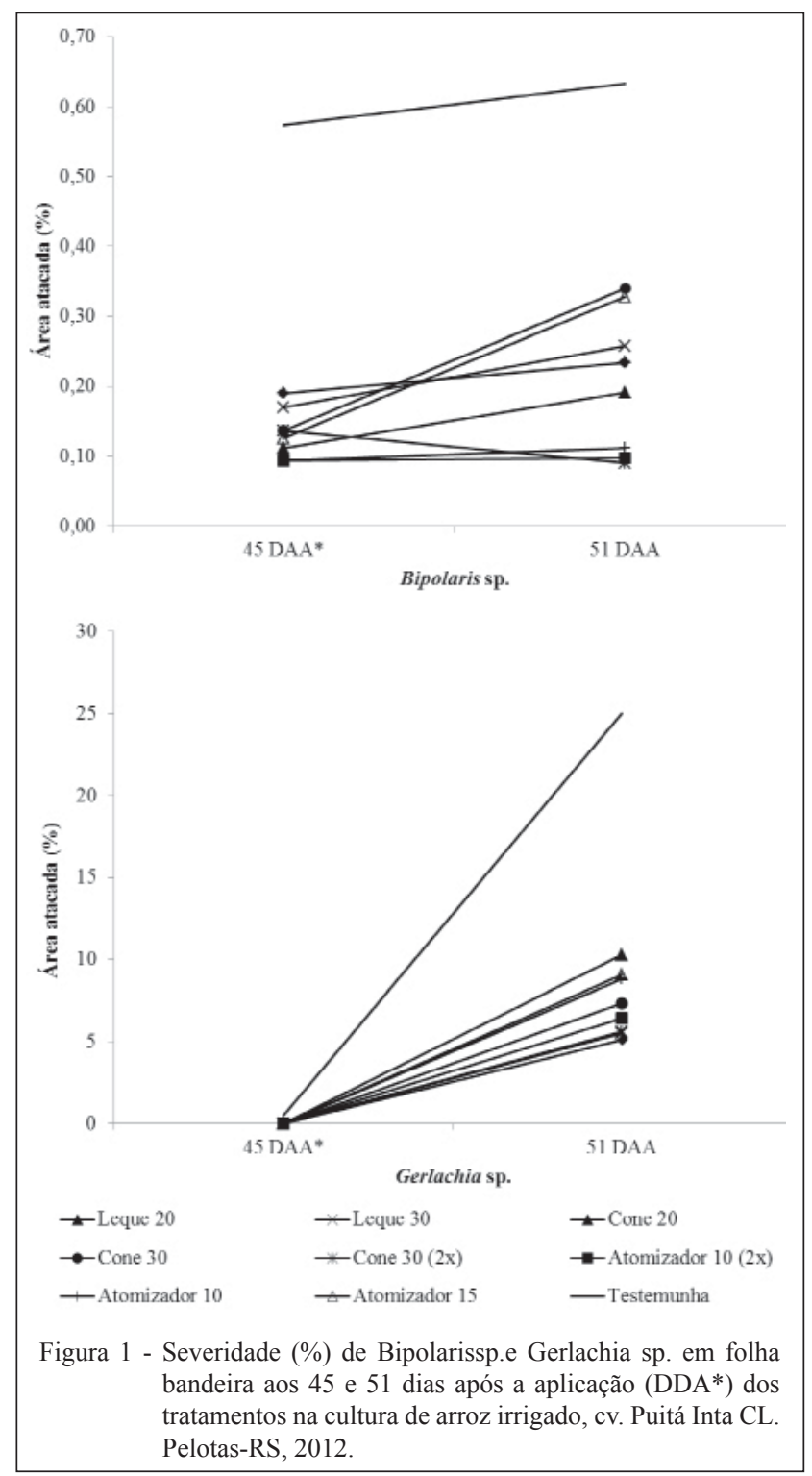

de misturas de triazóis com estrobilurinas, em duas aplicações.

O maior peso de grãos inteiros foi obtido no tratamento com bicos defletores com volume de $30 \mathrm{~L} \mathrm{ha}^{-1}$ (Tabela 2). BAYER et al. (2011) também encontraram maior peso de grãos inteiros quando usaram bicos leque, calibrados a 20L ha', com a cultivar 'Qualimax 1' e a mistura de fungicida trifloxistrobina + propiconazole.

$\mathrm{O}$ número de grãos gessados não diferenciou da testemunha, nos tratamentos com bico cônico a $30 \mathrm{~L} \mathrm{ha}^{-1}$ e atomizador rotativo de discos com volume $10 \mathrm{~L} \mathrm{ha}{ }^{-1}$ com duas aplicações. Este fato, seguramente está relacionado com a presença de percevejos que ocorreram na área experimental, mascarando os dados. $\mathrm{O}$ ataque foi intenso na fase final de maturação dos grãos, o que dificultou a análise, pois, além do aparecimento de manchas escuras na casca, provocam também manchas opacas (gessadas) no endosperma, em volta das perfurações causadas pelas picadas, fato que também já havia sido detectado por CASTRO et al. (1999).

Embora a incidência de doenças tenha sido baixa, as avaliações de sanidade dos grãos revelaram que o tratamento com fungicida reduziu consideravelmente a incidência de Fusarium sp. e Gerlachia sp. (Tabela 3). De acordo com FRANCO et al. (2001), a adoção do teste de sanidade nas sementes de arroz irrigado para comercialização pode prevenir a disseminação dos patógenos nas lavouras. Da mesma forma, CORNÉLIO et al. (2000) relataram 
Tabela 1 - Parâmetros de produtividade de arroz irrigado cv 'Puitá Inta CL' com a aplicação da mistura de fungicidas Azoxistrobina + Difenoconazol por meio de diferentes equipamentos e taxas de aplicação. Pelotas - RS, 2012.

\begin{tabular}{lccc}
\hline Tratamentos & Grãos por panícula & Peso de mil grãos (g) & \multicolumn{1}{c}{ Produtividade (kg ha $\left.{ }^{-1}\right)$} \\
\hline BL 20 & $167,56 \mathrm{a}^{*}$ & $22,67 \mathrm{c}$ & $12.428 \mathrm{a}$ \\
BL 30 & $150,62 \mathrm{ab}$ & $24,09 \mathrm{abc}$ & $11.198 \mathrm{ab}$ \\
BC 20 & $145,66 \mathrm{ab}$ & $24,98 \mathrm{ab}$ & $12.547 \mathrm{a}$ \\
BC 30 & $135,04 \mathrm{~b}$ & $24,73 \mathrm{ab}$ & $10.701 \mathrm{ab}$ \\
BC 30 (2x) & $139,35 \mathrm{ab}$ & $23,69 \mathrm{bc}$ & $10.828 \mathrm{ab}$ \\
ATM 10 (2x) & $142,89 \mathrm{ab}$ & $25,75 \mathrm{a}$ & $9.309 \mathrm{~b}$ \\
ATM 10 & $127,65 \mathrm{~b}$ & $25,12 \mathrm{ab}$ & $11.410 \mathrm{ab}$ \\
ATM 15 & $141,09 \mathrm{ab}$ & $25,03 \mathrm{ab}$ & $10.280 \mathrm{ab}$ \\
Testemunha & $132,99 \mathrm{~b}$ & $23,7 \mathrm{bc}$ & $10.488 \mathrm{ab}$ \\
Valor F & 3,02 & 5,36 & 4,34 \\
Pr $>$ F & 0,0107 & 0,0002 & 0,001 \\
CV $(\%)$ & 10,498 & 3,750 & 9,978 \\
\hline
\end{tabular}

*Médias com letras iguais na coluna não diferem entre si pelo teste de Tukey $(\mathrm{P}<0,05)$.

que o estudo da relação entre a ocorrência da doença no campo e a presença do patógeno na semente é de grande importância na determinação dos padrões de tolerância do fungo na semente. FRANCO et al. (2001), avaliando fungos associados a sementes de arroz irrigado, encontraram maior incidência de Nigrospora oryzae, 16,3\%; Gerlachia oryzae, $18,0 \%$; Bipolaris oryzae, 2,6\%; Penicillum sp., $34,4 \%$. Os resultados foram semelhantes apenas para Gerlachia oryzae, enquanto que, para Nigrospora sp. e Bipolaris sp., os resultados foram totalmente discrepantes, mesmo levando-se em consideração a baixa incidência de doenças na lavoura (Tabela 3).

\section{CONCLUSÃO}

Nas condições em que o trabalho foi realizado, conclui-se que:

- A aplicação da mistura dos fungicidas Azoxistrobina + Difenoconazol, independente dos equipamentos testados, resulta em menor severidade das doenças Bipolaris sp. e Gerlachia sp. nas folhas e menor incidência de Fusarium sp. e Gerlachia sp. nos grãos.

- Mais uma aplicação, 15 dias após a primeira, não difere dos demais tratamentos.

Tabela 2 - Renda e rendimento de grãos de arroz cv. 'PuitáInta CL'. Peso de grãos gessados, manchados, quebrados sem defeitos e inteiro sem defeitos. Pelotas-RS, 2012.

\begin{tabular}{|c|c|c|c|c|}
\hline \multirow{2}{*}{ Tratamentos } & \multicolumn{2}{|c|}{---------------Defeitos (g)---------------- } & \multicolumn{2}{|c|}{ 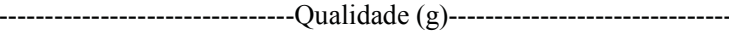 } \\
\hline & Grãos gessados & Grãos manchados & Grãos Quebrados sem defeitos & Grãos Inteiros sem defeitos \\
\hline BL 20 & $0,79 \mathrm{ab}^{*}$ & $0,38 \mathrm{a}$ & 6,87 a & $55,86 \mathrm{ab}$ \\
\hline BL 30 & $0,77 \mathrm{ab}$ & $0,46 \mathrm{a}$ & $8,14 \mathrm{a}$ & $56,01 \mathrm{a}$ \\
\hline BC 20 & $0,55 \mathrm{abc}$ & $0,49 \mathrm{a}$ & $7,18 \mathrm{a}$ & $54,44 \mathrm{ab}$ \\
\hline BC 30 & $0,46 \mathrm{abc}$ & $0,20 \mathrm{a}$ & $11,83 \mathrm{a}$ & $49,37 \mathrm{ab}$ \\
\hline BC $30(2 x)$ & $0,74 \mathrm{a}$ & $0,28 \mathrm{a}$ & $11,38 \mathrm{a}$ & $49,22 \mathrm{ab}$ \\
\hline ATM $10(2 x)$ & $0,84 \mathrm{a}$ & $0,57 \mathrm{a}$ & $8,51 \mathrm{a}$ & $45,94 b$ \\
\hline ATM 10 & $0,27 b c$ & $0,36 \mathrm{a}$ & $9,00 \mathrm{a}$ & $52,96 \mathrm{ab}$ \\
\hline ATM 15 & $0,19 \mathrm{c}$ & $0,33 \mathrm{a}$ & $10,44 \mathrm{a}$ & $52,17 \mathrm{ab}$ \\
\hline Testemunha & $0,97 \mathrm{a}$ & $0,66 \mathrm{a}$ & $7,55 \mathrm{a}$ & $51,73 \mathrm{ab}$ \\
\hline Valor F & 5,58 & 1,74 & 2,24 & 2,25 \\
\hline $\operatorname{Pr}>F$ & $<.0001$ & 0,1019 & 0,0326 & 0,0319 \\
\hline CV (\%) & 16,73 & 22,00 & 22,91 & 13,55 \\
\hline
\end{tabular}

*Medias com letras iguais na coluna não diferem entre si pelo teste de Tukey $(\mathrm{P}<0,05)$.

Ciência Rural, v.44, n.8, ago, 2014. 
Tabela 3 - Incidência de patógenos em grãos de arroz oriundos das parcelas tratadas com fungicida Azoxistrobina + Difenoconazol aplicados com diferentes taxas e equipamentos de aplicação. Pelotas-2012.

\begin{tabular}{|c|c|c|c|c|c|}
\hline Tratamentos & Bipolaris sp. & Nigrospora sp. & Fusarium sp. & Alternaria sp. & Gerlachia sp. \\
\hline BL 20 & $77,0 \mathrm{a} *$ & $73,4 \mathrm{a}$ & $7,2 \mathrm{a}$ & $2,6 a$ & $3,0 \mathrm{a}$ \\
\hline BL 30 & $81,2 \mathrm{a}$ & $63,8 \mathrm{a}$ & $4,8 \mathrm{a}$ & $1,8 \mathrm{a}$ & $2,2 \mathrm{a}$ \\
\hline BC 20 & $66,2 \mathrm{a}$ & $60,4 \mathrm{a}$ & $4,4 a$ & $1,4 \mathrm{a}$ & $2,2 \mathrm{a}$ \\
\hline BC 30 & $74,6 \mathrm{a}$ & $57,6 \mathrm{a}$ & $4,4 a$ & $3,2 \mathrm{a}$ & $1,8 \mathrm{a}$ \\
\hline BC $30(2 x)$ & $39,8 \mathrm{a}$ & $74,8 \mathrm{a}$ & $4,8 \mathrm{a}$ & $2,6 \mathrm{a}$ & $1,8 \mathrm{a}$ \\
\hline ATM $10(2 x)$ & $71,2 \mathrm{a}$ & $75,4 \mathrm{a}$ & $3,8 \mathrm{a}$ & $2,8 \mathrm{a}$ & $1,4 \mathrm{a}$ \\
\hline ATM 10 & $46,6 \mathrm{a}$ & $67,0 \mathrm{a}$ & $4,2 \mathrm{a}$ & $6,0 \mathrm{a}$ & $3,4 \mathrm{a}$ \\
\hline ATM 15 & $49,6 \mathrm{a}$ & $60,6 a$ & $3,4 \mathrm{a}$ & $4,6 \mathrm{a}$ & $1,0 \mathrm{a}$ \\
\hline Testemunha & $56,6 \mathrm{a}$ & $62,4 a$ & $21,2 b$ & $1,8 \mathrm{a}$ & $14,4 \mathrm{~b}$ \\
\hline Valor F & 2,46 & 0,21 & 5,4 & 1,4 & 4,96 \\
\hline $\operatorname{Pr}>F$ & 0,0307 & 0,9862 & 0,0002 & 0,229 & 0,0003 \\
\hline $\mathrm{CV}(\%)$ & 33,84 & 23,08 & 34,56 & 38,75 & 43,54 \\
\hline
\end{tabular}

*Médias com letras iguais na coluna não diferem entre si pelo teste de Tukey $(\mathrm{P}<0,05)$.

\section{AGRADECIMENTOS}

Gostaríamos de agradecer ao Conselho Nacional de Desenvolvimento Científico e Tecnológico (CNPq) pelo auxílio financeiro em forma de bolsa de Doutorado $\left(\mathrm{n}^{\circ}\right.$ processo 140688/2009-9).

\section{REFERÊNCIAS}

AMATO, G.W.; ELIAS, M.C.A. Parboilização do arroz. Porto Alegre: Ricardo Lenz Editor, 2005. V.1, 160p.

ARAÚJO,E.C.; GONTOW, M. Estudo do mercado da aviação agrícola. Botucatu: Agrotec e Embraer, 1993. Np.

BALARDIN, R.S.; BORIN, R.C. Doenças na cultura do arroz irrigado. Santa Maria: UFSM, 2001. 48p.

BAYER, T. et al. Equipamentos de pulverização aérea e taxas de aplicação de fungicida na cultura de arroz irrigado. Revista Brasileira de Engenharia Agrícola e Ambiental, v.15, n.2, p.192-198, 2011. Disponível em: <http://www.scielo.br/scielo. php?pid $=$ S1415-43662011000200007\&script $=$ sci_arttext $>$. Acesso em: 10 dez. 2012. doi: 10.1590/S1415-43662011000200007.

BRASIL. Instrução Normativa 06 de março de 2010 do MAPA. Normas de identidade e qualidade do arroz, 2010, [S. 1.].

BRASIL. Ministério da Agricultura e Reforma Agrária. Amostragem. In: . Regras para análise de sementes. Brasília: SNAD/DNDV/CLAV, 1992. Cap.1, p.13-54.

CASTRO, E da M. de. et al. Qualidade de grãos em arroz. Santo Antônio de Goiás: Embrapa Arroz e Feijão, 1999. 30p. (Embrapa Arroz e Feijão. Circular Técnica, 34). Disponível em: $<$ http://ainfo. cnptia.embrapa.br/digital/bitstream/CPAF-AC-2009-09/20554/1/ circ_34.pdf>. Acesso em: $18 \mathrm{dez} .2012$.

CELMER, A.F.; BALARDIN, R.S. Dano devido a doenças foliares no arroz irrigado. In: CONGRESSO BRASILEIRO DE ARROZ IRRIGADO, 2003, Balneário Camboriú, SC. Anais... Itajaí: EPAGRI. 2003. p.326-327.
CELMER, A. et al. Controle químico de doenças foliares na cultura do arroz irrigado. Pesquisa Agropecuária Brasileira, v.42, n.6, p.901-904, 2007. Disponível em: <http://www.scielo.br/scielo. php?script $=$ sci_arttext\&pid=S0100-204X2007000600019\&lng $=$ en\&nrm=iso\&tlng=pt>. Acesso em: 10 out. 2012. doi: 10.1590/ S0100-204X2007000600019.

CORNÉLIO, V.M.O. et al. Associação entre a incidência de brusone e a presença de Pyricularia grisea nas sementes de arroz. Pesquisa Agropecuária Brasileira, v.35, n.3, p.639-645, 2000. Disponível em: $<\mathrm{http}: / / \mathrm{www}$. scielo.br/scielo.php?script $=\mathrm{sci}$ arttext\&pid=S0100-204X2000000300021>. Acesso em: 10 out. 2012. doi: 10.1590/S0100-204X2000000300021.

CORRÊA, C.L. Sobrevivência de Bipolaris oryzae em sementes de arroz armazenadas sob duas condições ambientais. 2006. 36f. Dissertação (Mestrado em Ciências) - Curso de Pós-graduação em Ciência e Tecnologia de Sementes, Universidade Federal de Pelotas.

COUNCE, P.A. et al. A uniform, objective, and adaptative system for expressing rice development. Crop Science, v.40, n.2, p.436443, 2000. Disponível em: <https://www.crops.org/publications/ cs/articles/40/2/436>. Acesso em: 10 nov. 2012. doi: 10.2135/ cropsci2000.402436x.

DALLAGNOL, L. et al. Influência das doenças foliares no rendimento de grãos na cultura do trigo. Revista FZVA, v.13, n.2, p.139-137, 2006. Disponível em: <http://revistaseletronicas.pucrs.br/ojs/index. php/fzva/article/view/2361/1848>. Acesso em: 10 jan. 2013.

FAGERIA, N.K.; PRABHU, A.S. Controle de brusone e manejo de nitrogênio em cultivo de arroz irrigado. Pesquisa Agropecuária Brasileira, v.39, n.2, p.123-129, 2004. Disponível em: <http:// www.scielo.br/scielo.php?script $=$ sci_arttext\&pid $=\mathrm{S} 0100$ 204X2004000200004>. Acesso em: 10 nov. 2012. doi: 10.1590/ S0100-204X2004000200004.

FRANCO, D.F. et al. Fungos associados a sementes de arroz irrigado no Rio Grande do Sul. Revista Brasileira de Agrociência, v.7, n.3, p.235-236, 2001. Disponível em: <http://www2.ufpel.edu. br/faem/agrociencia/v7n3/artigo16.pdf $>$. Acesso em: 10 dez. 2012.

MACIEL, J.L.N.; TRONCHONI, J.G. Avaliação de fungicidas para o controle de doenças da parte aérea do cultivar 'IRGA 417'. 
In: CONGRESSO BRASILEIRO DE ARROZ IRRIGADO, 2003, Balneário Camboriú, SC. Anais... Itajaí: EPAGRI, 2003. p.332-333.

MAPA. Regras para análise de sementes. Ministério da Agricultura, Pecuária e Abastecimento. Secretaria de Defesa Agropecuária. Brasília: Mapa/ACS, 2009. 399p.

MARZARI, V. et al. População de plantas, dose de nitrogênio e aplicação de fungicida na produção de arroz irrigado: I - Características agronômicas. Ciência Rural, v.37, n.2, p.330-336, 2007. Disponível em: <http://www.scielo.br scielo.php? pid $=\mathrm{S} 0103-84782007000200006 \&$ script $=$ sci arttext>. Acesso em: 10 nov. 2012. doi: 10.1590/S010384782007000200006 .

OTTONI, G. et al. Eficiência de fungicidas no controle de manchaparda (Bipolaris oryzae) em arroz (Oryza sativa). Pesquisa Agropecuária Tropical, v.30, n.2, p.59-62, 2000. Disponível em: <http://www.revistas.ufg.br/index.php/pat/article/view/2786>. Acesso em: 20 set. 2012.

PRABHU, A.S.; FILIPPI, M.C. Arroz (Oryza sativa) Controle de doenças. In: VALE, F.X.R.; ZAMBOLIN, L. Controle de doenças de plantas: grandes culturas. Viçosa: Universidade Federal de Viçosa, 1997. V.1, p.51-79.

SLATON, N.A. et al. Sheath blight severity and rice yield as affected by nitrogen fertilizer rate, application method and fungicide. Agronomy Journal, v.95, n.6, p.1489-1496, 2003. Disponível em: $<$ https://www.agronomy.org/publications/aj/articles/95/6/1489>. Acesso em: 10 nov. 2012. doi: 10.2134/agronj2003.1489.

ZEMOLIN, C.R. Manejo de nitrogênio e tratamento químico sobre a ocorrência de Tilletia barclayana em arroz irrigado. 2009. 66f. Dissertação (Mestrado em Agronomia) - Curso de PósGraduação em Agronomia, Universidade Federal de Santa Maria. 